\title{
Air quality solutions need to be embedded in mainstream consciousness
}

\author{
E. Hayes ${ }^{1}$ \\ ${ }^{1}$ University of the West of England
}

Over half of the world's population currently live in urban areas. Although the global population growth rate is declining, the global population is increasing and is expected to reach 9.6 billion by 2050 , with an estimated $70 \%$ living in towns and cities ${ }^{1}$. This growing population will create more demands on an increasingly stressed planet with limited resources. It will be cities and the associated industrial and commercial activities that will demand the majority of the $40 \%$ increase in world energy forecast by 2030 . It will be cities that will demand the majority of the $70 \%$ increase in food forecast by 2025 . It will be in cities where the growing middle classes will be the main consumers of electricity, oil, food beverages, household appliances, cars and other goods and service ${ }^{2}$. This is a potential recipe for continued poor air quality and illustrates the importance of integrated multi-stakeholder strategic planning and coordinated management.

While society may choose air pollution as a consequence of our activities, the willingness of society to accept air pollution has diminished in recent years in parallel with an increase in the public's environmental awareness and health consciousness, although the level of acceptance varies around the globe. This growth in air pollution awareness has largely been coupled with the surge in social media and the availability of publically accessible evidence in recent years. The World Health Organization (WHO) recently reported that seven million people were estimated to have died as a result of air pollution in 2012 and that one in eight global deaths were linked to air pollution making it "the world's largest single environmental health risk"3. Air pollution, its health and ecological impacts, are now front page news and should, you would hope, result in the atmosphere, our largest and largely 'forgotten' ecosystem habitat, to no longer be taken for granted. Clean air is the the ultimate public good, and it is vital that air no longer falls foul of the 'Tragedy of the Commons' for example with private advantage gains from emissions into the atmosphere depleting its value as a public good.

The WHO report illustrated that the impact of air pollution does not respect boundaries and revealed a stronger causal link between both indoor and outdoor air pollution exposure and cardiovascular disease, as well as cancer. The key sources of air pollution may vary around the world, from indoor pollution due to heating and cooking in parts of Africa and Asia, to ambient pollution from transport and industry in all of our growing cities, but with poor ambient air quality projected to be the world's leading environmental cause of mortality by 2050 , ahead of dirty water and lack of sanitation ${ }^{4}$, a common and integrated effort is required to address the issue.

Fittingly, the release of these WHO findings coincided with the March/April 2014 smog episode across Europe. London experienced elevated concentrations of $\mathrm{PM}_{10}$ and $\mathrm{PM}_{2.5}$ due to a combination of local and transboundary pollution from Europe with some Saharan dust. During the same episode, Paris had to take drastic action, restricting cars entering the city depending on their licence plates (odd/even days) as an emergency measure to improve air quality. The mainstream media engaged and air pollution and its health implications were, albeit briefly, part of our everyday news thereby raising its public and political profile. The air quality community was bombarded by media requests for information, interviews and sound-bites, but what was striking was the widespread lack of concern and apparent ignorance of air pollution on a day-to-day basis in contrast to the mass outcry once air quality concentrations got to extreme 'media frenzy' levels.

As air quality practitioners, we have an ongoing duty to undertake and deliver air quality management and research based on sound science, robust evidence and provide an impactful contribution to knowledge. The Clean Air Journal and the activities of the National Association for Clean Air (NACA) play a vital role in dissemination of new knowledge but recent events have again illustrated the importance of the air quality community's additional role as science communicators and educators to ensure we engage key stakeholder, have public participation in our activities and where possible, build capacity and capabilities. Not an easy task but essential to ensure that air quality problems and more importantly, air quality solutions are embedded as part of mainstream consciousness now and in the future.

\footnotetext{
1 United Nations, 2014, World Population Prospects: The 2012 Revision, Methodology of the United Nations Population estimates and Projection, ESA/PMP.235

${ }^{2}$ World Economic Forum, 2011. Water Security; The Water-Food-Energy-Climate Nexus, Island Press

${ }^{3}$ http://www.who.int/mediacentre/news/releases/2014/air-pollution/en/

${ }^{4}$ OECD (2012). OECD Environmental Outlook to 2050: the Consequences of Inaction. 350pp.
} 